\title{
HOW TO MEASURE THE SAFETY CULTURE OF ORGANIZATIONS
}

\section{Martin Halaj ${ }^{1}$}

\begin{abstract}
Every organization has an interest in protecting its assets and increasing its profit. To preserve the integrity, organizations generally ensure their assets are safe. Today, especially in large organizations, asset security is a chief priority in decision-making. A factor affecting the level of an organization's security is its safety culture. This factor is measured by the level by which the organization and its employees adopt and comply with security rules and principles. The status of a safety culture can have a positive or negative impact on the organization's security, which directly affects its development. The aim of this article is to describe approaches for assessing the safety culture of different organizations. The study results can be used to compare several organizations, and it is possible to identify differences in the level of safety culture after applying innovative changes.
\end{abstract}

UDC Classification: 304; DOI: http://dx.doi.org/10.12955/cbup.v5.996

Keywords: safety, safety culture, corporate culture

\section{Introduction}

A factor affecting an organization's security is its safety culture. Organizations and their employees have specific values, traditions, attitudes, and approaches towards security issues. A summary of these characteristics represents the safety culture of organizations and individuals. Components of the safety culture of organizations are human, material, and intellectual resources. Each organization is interested in recognizing the level of its safety (including occupational safety and security of assets). While assessing the complex level of safety, it is necessary to determine the degree to which the safety culture has been implemented within the organization. Therefore, it is important to know the possibility of measuring safety culture, which may be different for each organization. Methods of measuring safety culture are specific and use different input data. Depending on the structure of organizations, methods of measuring safety culture differ and can intervene in various sectors of the organization. This article describes the possibilities of measuring safety culture in different organizations.

\section{Literature Review}

Since the existence of human civilization, influencing the safety of national or religious cultures prevails to achieve objectives or obtain domination. Today, this phenomenon persists with the ordinary person starting to realize its importance. In the past, as well as now, conflicts between different cultures ended with the loss of life. The impact of culture on safety is accompanied by power and violence to promote and impose certain values. On the other hand, there is a defense mechanism to protect values, norms, and attitudes (Hofreiter, 2015).

The term safety culture, which combines the concept of safety and culture, was introduced in 1986 by a group of workers of the International Atomic Energy Agency (IAEA) after an accident in a nuclear reactor at Chernobyl (Lardner, 2003). The investigative team that examined the accident stated that the main reason for the overheating reactor were shortcomings in the safety culture of the organization. Since this event, safety culture has become a focus in optimizing corporate culture so that employees are united in their behavior towards safety (Slováčková, 2015). Instruction under the Assessment of Safety Culture in Organizations Team (ASCOT), IAEA-TECDOC-860, issued in 1996, suggests a set of key indicators to be taken into account for the different areas of an organization when evaluating its safety culture (Václav \& Sivák, 2016).

Over time, the safety culture introduced in nuclear facilities was incorporated into other sectors of industry. Safety culture is not specifically intended for personnel at risk or dangerous objects but refers to individuals, groups, and society as a whole. Safety culture began to be used as a means of reducing or eliminating the impact of adverse events and factors for individuals, social groups, and states (Hofreiter, 2015).

The definitions of the safety culture are unique and differ among authors. Cieslarczyk (2011) considered a safety culture as a way of thinking about safety (what is safety, the possibility of

\footnotetext{
${ }^{1}$ Faculty of Security Engineering, University of Žilina, Slovakia, martin.halaj@fbi.uniza.sk
} 
expressing safety), the perception of safety, and detection of safety values (how to achieve safety, which techniques and technologies can be used to achieve safety).

Pidgeon (1991) defines the safety culture as "the set of beliefs, norms, attitudes, roles, and social and technical practices that are concerned with minimizing the exposure of employees, managers, customers and members of the public to conditions considered dangerous or injurious" (cited in Guldenmund, 2010, p. 25).

However, a well cited definition from the United Kingdom Health and Safety Commission (HSC, 1993, p. 23) states that "the safety culture of an organization is the product of individual and group values, attitudes, perceptions, competencies, and patterns of behavior that determine the commitment to, and the style and proficiency of, and organization's health and safety management". According to available sources, one can define safety culture as a set of values, traditions, characteristics, and attitudes of organizations and individuals in which the safety of the organizations has top priority and which adequate attention must be given in view of such importance (Kirschstein, 2013)

Safety culture is a part of the internal safety environment of an organization and reflects the perception and assurance of an organization's safety. The safety issues are often subjective, due to a variety of persistent attitudes, opinions, and values of individual employees. Safety culture acquires many forms, and its existence or effectiveness is influenced by several factors, such as norms, values, symbols, conditions, conduction, and speech.

For an understanding of the safety culture, it is necessary to identify artifacts, values, and assumptions that are part of the safety culture. Artifacts are most easily traceable, but their interpretation is often challenging. The level of artifact acquires understanding after becoming aware of the values and assumptions (SAFETY CULTURE IN NUCLEAR EQUIPMENT: Instructions for use in enhancing safety culture, 2010).

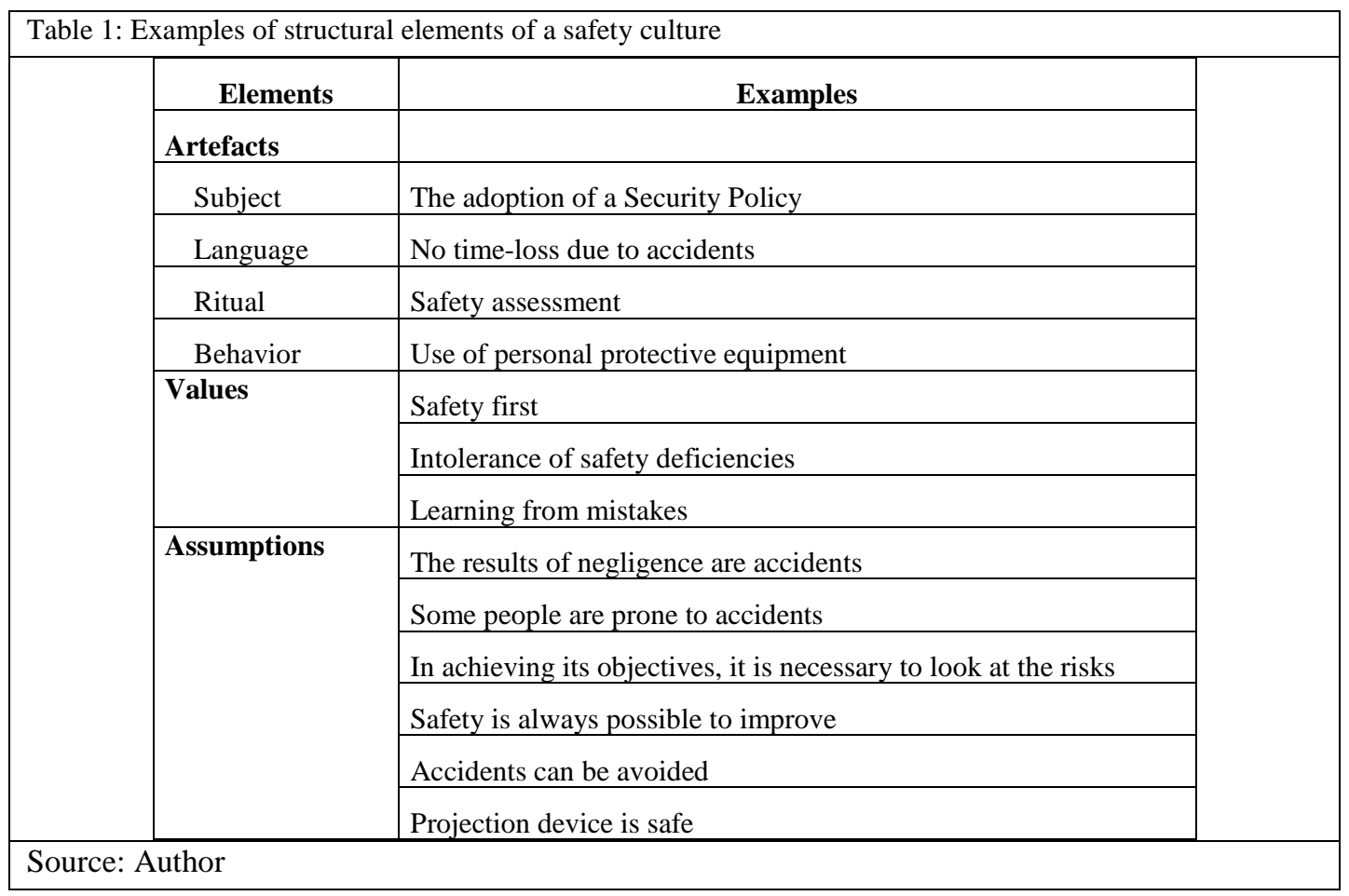

Safety culture can be assessed at levels of the individual, the organization, or the state. Safety culture at the organizational level requires the acceptance of safety to achieve and ensure the safety of the organization. There is a particular emphasis on occupational safety and health, and protecting staff in their activities.

In creating the organization's security policy, the managers are important, as are the professional competencies of employees, which are necessary for finding results in adverse events of each sector of the organization. The organization's safety culture is based on the reception and identification of 
employees with the organization's security policy, as well as on safety behavior within the organization (Halaj, 2016).

Hofreiter (2015) states that the organization's safety culture is influenced by:

- Adoption of security by senior management;

- Allocating sufficient resources to safety;

- Quality safety documentation and safety procedures;

- Strict observance of safety in all sectors of the organization;

- Safety training and educations;

- The readiness of the organization to deal with crisis adverse events assigned forces and means which are permanently accessible;

- Regular checks, obstruction, and continuously improving organization's safety.

- Safety culture affects safety management due to the existence of rules, laws, regulations, and standards in the field of security. The introduction and the presence of safety culture in an organization influences the management of the whole organization and behavior of senior management on issues of security and the adoption of security policy. Organization adopts security policy, which involves an important and basic document confirming an organization's efforts to address security issues in all sectors of the organization. It contains a description of the organization's protected interests as well as potential risks. A security policy can be processed comprehensively organization-wide or individually for each sector separately (Halaj, 2016).

\begin{tabular}{|l|l|}
\hline Figure 1: Application of safety culture at the level of the organization \\
\hline Safety culture \\
Source: Author \\
security policy
\end{tabular}

\section{Measuring Safety Culture}

The measurement of the safety culture of an organization is focused on sustained and long-term improvement of safety and the safety culture within the organization. The outcome of a safety culture can be quantified by its status throughout the organization, and within the various sub-sectors that are part of the safety culture. Based on these measurements one can determine the current level of the organization, and then take appropriate safety strategies or adopt a security policy responsible for its needs.

\section{Quantitative Measurement of an Organization's Safety Culture}

In addition to the quantitative measurement of a safety culture, collecting input data, mostly through questionnaires, is a vital phase of the process. The significance of this phase requires a large number of respondents to the questionnaires. Input data are analyzed to obtain the most objective understanding of the relationship between the organization and its safety culture. This data can be extended with information from an organization's safety history concerning frequency of accidents, incidents, and other statistical indicators. Concerning the questionnaire, it is appropriate to involve senior management of each organization.

The main focus of quantitative measurements of safety culture should be on the following (Slováčková, 2015):

- Plans and objectives of organization's safety;

- Organization and regulation of the safety;

- Management of the safety;

- Tools

- Analysis of accidents and injuries;

- Safety education; 


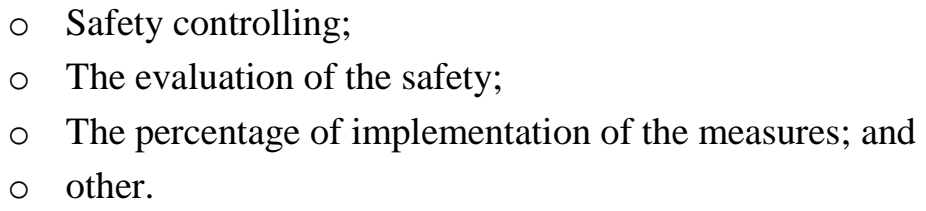

Obtained input data in each area are evaluated, and the result of analysis can be presented in a safety culture grid (Figure 2) and as a safety culture coefficient (Kirschstein, 2013).

A safety culture grid is a way of visualizing the measured results (Kirschstein \& Werner-Keppner, 2014). It presents the strengths and weaknesses of the organization for each area of the safety culture (Slováčková, 2015). Subsequently, it is possible to measure the safety culture to the required level.

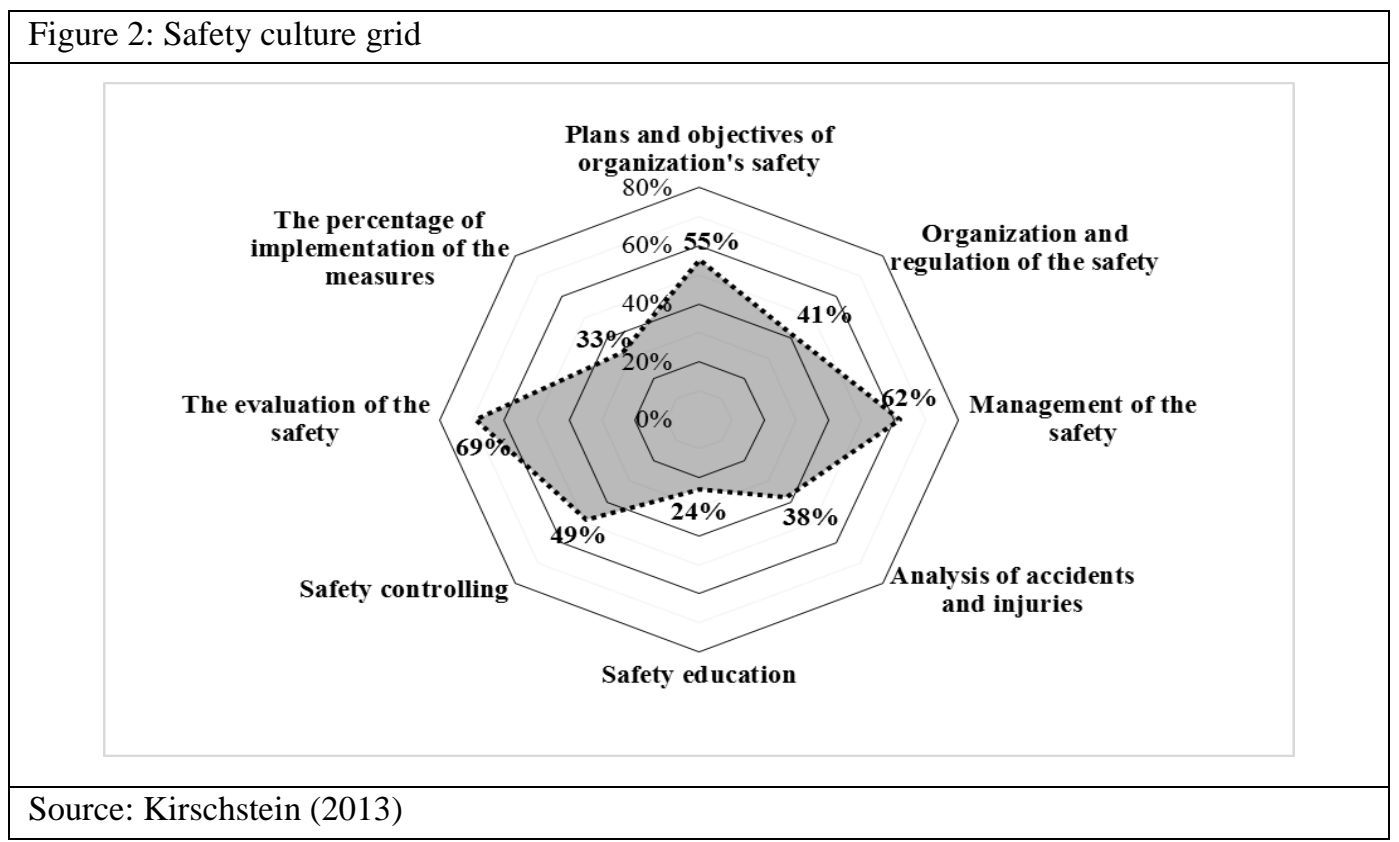

Safety culture coefficient unifies and summarizing the results for each area into one numerical expression that reflects the level of the safety culture in the organization. The safety culture coefficient can be used to compare two or more organizations for safety culture and allocate categories (weak, medium, or strong levels of safety culture) to the organizations.

Qualitative Measurement of Organization's Safety CultureIn cases where there is insufficient information to identify and determine the level of safety culture by quantitative means, qualitative methods can be used. In this approach, appropriate data can be collated through controlled interviews of staff based on structured questionnaires. According to Halaj (2016), data can be obtained from two levels of staff:

1. Senior management; and

2. Regular employees.

In both levels, questions addressed to the respondents should involve all areas of safety culture and include the main factors likely to affect the safety culture of the organization. Respective questions regarding the factors influencing the final level of safety culture are especially relevant in manufacturing, where the safety culture is of the highest importance. Responses and reactions of respondents can be recorded by field notes or audio recordings.

The aim of controlled interviews with management and regular employees is to obtain data about safety and safety culture implemented in the organization. Answers on particular issues related to the elements of safety culture may differ. A critical step involves an expert or group of experts responsible for analyzing the collected data. Their purpose is to identify the quality and appropriateness of responses and eliminate any that are flawed.

The final step in the qualitative approach is the verbal evaluation of the researched safety areas. This evaluation may have different scales, such as for observing safety: primary, important, secondary, or 
irrelevant; the reliability of technical equipment: excellent, very good, good, satisfactory, or poor; or compliance with laws, standards, and norms. Experts determine the level of safety culture in each organization from partial qualitative assessments, and determine the final level using a prepared scale (e.g., very weak, weak, not weak, not strong, strong, or very strong), which is the aim of qualitative measurement.

\section{Potential Problems of Measuring the Safety Culture}

One of the most important steps in assessing the safety culture involves choosing the appropriate method. A factor influencing method selection is the type of organization. For example, in manufacturing, safety extends to sectors other than those found in non-manufacturing organizations.

Selecting appropriate methods for measuring safety culture also relates to the size of the organization. Large organizations may have complex structures, and during the assessment, it is necessary to investigate all sectors. In these cases, due to time constraints, it is essential to use quantitative methods. It is also important to determine in advance how many respondents will need to participate in the assessment of safety culture using qualitative or quantitative methods.

The candor of respondents involved in the assessment is also crucial. Managers may often hide certain information in an attempt to appear the best in comparison with others. Regular employees may also hide information because they fear reprisal from their superiors if they respond to the detriment of the organization. Therefore, it is necessary to maintain the anonymity of participating respondents.

\section{Conclusion}

Safety culture is one factor that can significantly affect the complex integrity level of organizations. It reflects an organization's approach to safety and success of introducing in-house safety strategies. Hence, it is important to assess the level of safety culture in organizations. For this purpose, it is necessary to define the methods for assessing safety culture as well as choosing the appropriate method for a particular organization. This choice depends on the type, orientation, and size of the organization. Measuring safety culture involves either a qualitative or quantitative assessment of the level of safety culture. Organizations that are dissatisfied with the level of its safety culture can adopt new strategies. After this adoption, the level of safety culture within the organization may increase and thus enhance its safety status. However, where the organization intends to increase the level of safety, the elements involved should be included in the future assessment of its safety culture as these may influence the organization's safety status along with the security of active and passive components and assets of the organization. Finally, it is recommended that future research examines the interconnection of the safety culture and security of assets in the organizations.

\section{References}

(2010). SAFETY CULTURE IN NUCLEAR EQUIPMENT: Instructions for use in enhancing safety culture. Prague: State Office for Nuclear Safety and Research Institute for Occupational Safety.

Cieślarczyk, M. (2011). Culture of security and defense. Siedlce: Publisher of the University of Natural Sciences and Humanities.

Guldenmund, F. W. (2010). Understanding and exploring safety culture. Oisterwijk: Proefschriftmaken.nl.

Halaj, M. (2016). Safety culture as an aspect of organization security. Present and future development of security research (s. 35-44). Kraków: EDIS - publishing centre ŽU.

Health and Safety Commission (HSC). (1993). ACSNI Study Group on Human Factors. 3rd Report: Organizing for Safety. London: HMSO.

Hofreiter, L. (2015). Security culture and security management. Crisis Management(2), 63-68.

Kirschstein, G. (May 2013). How is possible to improve the quality of work safety and ensure a steady growth of the company's security culture? Safety and health at work.

Kirschstein, G., \& Werner-Keppner, E. (2014). How to measure a safety culture? Retrieved March 2, 2017, from Kirschstein: http://www.kirschstein.org/download/postergk-A4-cz.pdf

Lardner, R. (2003). Safety culture application guide. Edinburg.

Slováčková, I. (April 2015). Why and how to measure the safety culture of organization. Safety of work in practice, 2-4.

Václav, J., \& Sivák, J. (2016). Security culture - safety culture. Solving crisis situations in a specific environment (pp. $664-$ 668). Žilina: EDIS - publishing center ŽU. 